\title{
Haptoglobin gene diversity and incidence of uncomplicated malaria among children in lganga, Uganda
}

\author{
Catherine N. Lwanira ${ }^{1,4^{*}}$ (B), Fred Kironde ${ }^{1,2+}$ and Göte Swedberg ${ }^{3+}$
}

\begin{abstract}
Background: Haptoglobin $(\mathrm{Hp})$ is an acute phase protein that takes part in systemic regulation of haem during Plasmodium falciparum infections. Numerous genotypes of haptoglobin have been reported in malaria endemic populations. In this study, the relationship between haptoglobin genotypes and incidence of uncomplicated malaria in a cohort of children living in a malaria-endemic area of Uganda was determined.
\end{abstract}

Methods: This is an extension of a longitudinal study comprising of 423 children aged between six months and nine years, who were actively followed up for one year. Malaria episodes occurring in the cohort children were detected and the affected children treated with national policy drug regimen. Haptoglobin genotypes were determined by an allele-specific PCR method and their frequencies were calculated. A multivariate negative binomial regression model was used to estimate the impact of haptoglobin genotypes on incidence of uncomplicated malaria in the children's cohort. In all statistical tests, a P-value of $<0.05$ was considered as significant.

Results: The prevalence of the Hp 1-1, Hp 2-1 and Hp 2-2 genotypes in the children's cohort was 41\%, 36.2\% and $22.9 \%$, respectively. The overall frequency for the $\mathrm{Hp} 1$ allele was 59\%, while Hp 2 allele occurred at a frequency of $41 \%$. After adjustment of incidence rates for age, insecticide treated bed net (ITN) use and malaria history, the incidence of uncomplicated malaria for children carrying the Hp 2-2 genotype and those with the Hp 2-1 genotype was statistically similar $(P=0.41)$. Also, no difference in the incidence of uncomplicated malaria was observed between children carrying the Hp 1-1 genotype and those having the Hp 2-1 genotype ( $P=0.84)$ or between $\mathrm{Hp} 2-2 \mathrm{Vs} \mathrm{Hp}$ $1-1$ genotypes $(P=0.50)$.

Conclusions: This study showed that the $\mathrm{Hp} \mathrm{1-1} \mathrm{and} \mathrm{Hp}$ 2-1 genotypes each occur in nearly 4 in 10 children and the Hp 2-2 genotype occurs in 2 of every 10 children. No association with incidence of uncomplicated malaria was found. Additional studies of influence of haptoglobin genotypes on P. falciparum malaria severity are needed to understand the role of these genotypes in malarial protection.

Keywords: Haptoglobin genotypes, Plasmodium falciparum malaria, Incidence of uncomplicated malaria

*Correspondence: clwanira@gmail.com; clwanira@ucu.ac.ug

${ }^{\dagger}$ Fred Kironde and Göte Swedberg contributed equally to this work

${ }^{1}$ School of Biomedical Sciences, College of Health Sciences, Makerere University, PO Box 7072, Kampala, Uganda

Full list of author information is available at the end of the article

\section{Background}

Malaria is a major cause of morbidity and mortality among children below 5 years in sub-Saharan Africa [1]. The course of Plasmodium falciparum malaria infections involves interplay of both parasite and host factors such as host genetic variability [2]. In the blood stage of Plasmodium infection, merozoites multiply inside the red blood cells (RBCs) causing rupture of the $\mathrm{RBC}$ membrane

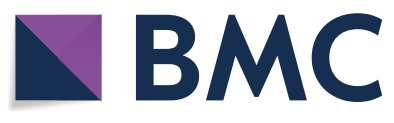

(c) The Author(s) 2020. This article is licensed under a Creative Commons Attribution 4.0 International License, which permits use, sharing, adaptation, distribution and reproduction in any medium or format, as long as you give appropriate credit to the original author(s) and the source, provide a link to the Creative Commons licence, and indicate if changes were made. The images or other third party material in this article are included in the article's Creative Commons licence, unless indicated otherwise in a credit line to the material. If material is not included in the article's Creative Commons licence and your intended use is not permitted by statutory regulation or exceeds the permitted use, you will need to obtain permission directly from the copyright holder. To view a copy of this licence, visit http://creativeco mmons.org/licenses/by/4.0/. The Creative Commons Public Domain Dedication waiver (http://creativecommons.org/publicdomain/ zero/1.0/) applies to the data made available in this article, unless otherwise stated in a credit line to the data. 
and release of free haemoglobin $(\mathrm{Hb})$ into circulation [3]. Tissue damage, inflammation, cytotoxicity [4] and host cell death [5] may follow as a result of accumulation of free haem. After 7-30 days from the time of the mosquito bite, malarial symptoms arise largely due to red blood cell rupture and the body's inflammatory response [3]. Haptoglobin (Hp) determines the course of Plasmodium infections by binding the free haem produced from intravascular lysis of the RBCs. Hp is secreted by the liver following acute infection and binds to free haem forming a stable haptoglobin- haemoglobin ( $\mathrm{Hp}-\mathrm{Hb})$ complex [6]. This complex is removed from circulation by binding to a cell-surface receptor (CD 163) expressed by monocytes or macrophages, then internalized and destroyed within the spleen [7]. This is needed in the control of free radical induced oxidative damage and inflammation that may follow $P$. falciparum infections [8].

In humans, $\mathrm{Hp}$ is encoded on the haptoglobin gene on chromosome $16 q 22.2$ [8]. The gene is polymorphic, with two co-dominant alleles ( $H p 1$ and $H p$ 2). The Hp 1 gene encodes two subunits; $\alpha 1$ and $\beta$ of approximately $8.86 \mathrm{kDa}$ and $40 \mathrm{kDa}$ respectively. The $\beta$ subunit shows no genetic polymorphism, while the $\alpha 1$ subunit has 2 allelic variants (IS and IF) that differ in amino acid composition and electrophoretic mobility. The Hp 2 gene encodes the $\alpha 2$ subunit of approximately $17.3 \mathrm{kDa}$ and a portion of the $\beta$-subunit [8]. The genetic arrangement depicted generates three major phenotypes ( $\mathrm{Hp} \mathrm{1-1,} \mathrm{Hp}$ 2-1 and Hp 2-2) [8] that vary in the binding affinities for free haem in the order, Hp 1-1> Hp 2-1> Hp 2-2 [7]. In earlier studies, Hp genotypes were found to be associated with altered plasma Hp levels $[9,10]$ and malaria outcomes [11]. The Hp 2-2 genotype that leads to lowest circulating plasma Hp levels [12] was associated with lower incidence of clinical malaria in prospective cohort studies carried out among African populations [13, 14]. Yet in another cohort study, the Hp 2-2 phenotype was associated with a higher susceptibility to $P$. falciparum infection among the Dogon, but not the Fulani, ethnic tribe of Mali [15]. In other studies where increased risk of developing $P$. falciparum symptomatic malaria among children carrying the Hp 2-2 genotype was reported [16], no associations between the Hp 1 allele and malaria susceptibility was found $[14,16]$.

The frequency of the Hp 1 and Hp 2 genes varies considerably in different populations. The $\mathrm{Hp} 1$ allele frequency ranges from as low as 0.07 in parts of India to over 0.7 in West Africa and South American populations [8]. Frequencies of the Hp 1 allele were found to be 0.52 among Hispanics, 0.55 in Blacks, 0.44 among Caucasians, 0.31 among Asians living in the American region and 0.56 in the African region [8]. In a study that examined the role of $\mathrm{Hp}$ polymorphisms in determining susceptibility to $P$. falciparum infection and severity of malaria among Ghanaian children, Hp1-1, Hp 2-1, and Hp 2-2 genotypes occurred in $32.4 \%$, 54.1\%, and 13.5\% children, respectively [17]. Two studies carried out in malaria endemic Kenyan coast found the prevalence of Hp 1-1, Hp 2-1 and Hp 2-2 phenotypes of $45 \%, 41 \%$ and $14 \%$ [13] and $28.5 \%, 45.2 \%$ and $26.4 \%$ of the study children, respectively [18]. In Uganda, there are no studies that have documented the frequency of Hp genotypes/ phenotypes in the population. This study reports about the profile of $\mathrm{Hp}$ genotypes and their relationship with incidence of uncomplicated malaria among children in Iganga, Uganda.

\section{Methods}

\section{Study design and setting}

This study is an extension of a longitudinal study that took place in the malaria endemic district of Iganga- Mayuge in eastern Uganda [19]. From September 2008 to October 2008, a team of well-trained home visitors engaged households to systematically recruit children into a baseline malaria study. Eligible children were enrolled into the baseline study and followed up for a period of one year from November 2008 to November 2009. The study cohort was recruited from a community living within six villages of Iganga district that are in close proximity to the malaria study clinic located at Makerere University Iganga/Mayuge Demographic Surveillance Site (MaKDSS). No interventional studies involving prophylactic anti-malarial mass treatment were undertaken in this study area at the time this study cohort was assembled. Inclusion criteria of the cohort study was as described in an earlier study [19] and followed; (1) six months to nine years of age; (2) agreement to come to the study clinic for any febrile episode or illness; (3) agreement to avoid medications administered outside the study; (4) agreement to remain in study area during the twelve months follow up; (5) absence of known chronic disease and 6) written informed consent provided by parent or guardian. Severely malnourished children (below $-3 z$ scores of the median World Health Organization (WHO) growth standards) [20] were excluded. Follow-up started when children fulfilled all of the selection criteria and were free of symptomatic malaria.

\section{Active case detection and estimation of malaria incidence}

Study villages were divided by convenience into active (nearby) villages and passive (more remote) villages. Study personnel sought for verbal consent from parents/guardians of the children to participate in a brief demographic survey, and written informed consent was obtained before enrolment into the study. Using a 
standardized questionnaire, demographics and malaria indicator information was collected. After enrolling into the study, parents or guardians were instructed to bring their children to the malaria clinic based at Iganga Hospital whenever the children felt unwell. Follow-up started when children fulfilled all of the selection criteria and were free of symptomatic malaria.

Children were visited twice a week by the study field workers at convenient times of day. A standardized questionnaire was administered for collecting information regarding illnesses that had occurred since the last visit, use of health care facilities and medications used. At each visit, the tympanic temperature was recorded using a digital thermometer. When fever (tympanic temperature of $\geq 37.5{ }^{\circ} \mathrm{C}$ ) or history of recent fever (within the last $24 \mathrm{~h}$ ) was observed or reported for any study child, a rapid diagnostic test $\left(\right.$ RDT, OPTIMAL ${ }^{\circledR}$ ) and microscopy of a stained blood smear were performed to screen for malaria and confirm the presence of malaria parasites, respectively. Uncomplicated malaria was confirmed using the WHO criteria that includes having any $P$. falciparum parasitaemia plus fever or a history of fever (within the past $24 \mathrm{~h}$ ) [21]. Children found with asexual malaria parasitaemia were followed up after being administered artemisinin-based combination therapy (ACT) according to Uganda national treatment guidelines [22]. Severely ill children were referred to Iganga Hospital. The time at risk for new infection was defined as the duration of study participation excluding 14 days after each ACTtreated episode of malaria. The incidence of malaria was determined by calculating the number of malaria episodes per child over the one year of active follow up.

\section{Sample preparation and DNA extraction}

Whole blood samples were obtained from all study children for subsequent DNA analyses. Blood samples were drawn into Ethylene Diamine Tetra Acetic acid (EDTA) anticoagulant tubes. Buffy coats were prepared from 1 to $2 \mathrm{ml}$ of whole blood by differential sedimentation using phosphate buffer saline (PBS) and 2\% fetal bovine serum (FBS). Genomic DNA was extracted from blood leukocytes using E.Z.N.A Blood DNA kit following the manufacturer's protocol (Omega Bio-tek, USA). DNA samples were stored at $-20{ }^{\circ} \mathrm{C}$ for subsequent genomic analysis.

\section{Haptoglobin genotyping}

Haptoglobin genotypes were determined by allelespecific polymerase chain reaction amplification as described before [23], using primers sets listed in Table 1. This was based on determination of the polymorphic alpha $(\alpha)$ chain alleles, Hp1 and Hp2. Hp1 encodes the $\alpha 1-1 S$ (slow form) and 1F (fast form) chains, while $\mathrm{Hp} 2$ encodes the $\mathrm{Hp} \alpha 2$ polypeptide chain. Primers F3 and C42 were used to amplify a $935 \mathrm{bp}$ fragment of the $\mathrm{Hp} 2$ allele. To amplify the $1.2 \mathrm{~kb}$ DNA fragments in the Hp1S allele, primers C51 and S2 were used (reaction S). For amplification of the $\mathrm{Hp} 1 \mathrm{~F}$ allele, primers $\mathrm{F} 3$ and $\mathrm{C} 72$ were used in reaction $\mathrm{F}$ to produce DNA fragment of $1.4 \mathrm{~kb}$.

\section{Polymerase chain reaction (PCR)}

PCR amplification was carried out in a $25 \mu \mathrm{L}$ reaction containing $10 \mathrm{mM}$ Tris $-\mathrm{HCl}(\mathrm{pH} 9.0), 50 \mathrm{mM} \mathrm{KCl}$, and $0.1 \%$ Triton X-100, $2.5 \mathrm{mM} \mathrm{MgCl} 2,200 \mu \mathrm{M}$ of each dNTP, $0.2 \mu \mathrm{M}$ of each primer and 1.5 units of Taq polymerase (Thermo Scientific, Inc). For each reaction, approximately $1 \mu \mathrm{L}$ of the DNA sample was used. After preheating at $95^{\circ} \mathrm{C}$ for $3 \mathrm{~min}$, PCR was performed with 35 cycles of heating at $94{ }^{\circ} \mathrm{C}$ for $40 \mathrm{~s}$, at $58{ }^{\circ} \mathrm{C}$ for $1 \mathrm{~min}$ and annealing at $72{ }^{\circ} \mathrm{C}$ for $2 \mathrm{~min}$. PCR products were separated by electrophoresis on $1.2 \%$ agarose gels stained with ethidium bromide. Hp genotypes were determined by observing the amplified DNA fragments under ultra violet light.

\section{Data management and analysis}

Data were cleaned, coded and entered into Microsoft Office Access ${ }^{\text {TM }}$ 2007. Descriptive statistics, Chisquare tests and multivariate analysis were carried out using Stata 12.0 (Stata Corp, College Station, Texas, USA). Allele and genotype frequencies were calculated. The association between haptoglobin genotype

Table 1 Primer sets for polymerase chain reaction

\begin{tabular}{|c|c|c|c|c|}
\hline Reaction & Target alleles & Primer pair & Oligonucleotide sequence $\left(5^{\prime}-3^{\prime}\right)$ & Product size (bp) \\
\hline \multirow[t]{2}{*}{ Reaction 2} & $\mathrm{Hp} 2$ & F3 & CAGGAGTATACACCTTAAATG & 935 \\
\hline & & $\mathrm{C} 42$ & TTACACTGGTAGCGAACCGA & \\
\hline \multirow[t]{2}{*}{ Reaction S } & Hp1S & C51 & GCAATGATGTCACGGATATC & $1.2 \mathrm{~kb}$ \\
\hline & & S2 & TTATCCACTGCTTCTCATTG & \\
\hline \multirow[t]{2}{*}{ Reaction F } & Hp1F & F3 & CAGGAGTATACACCTTAAATG & $1.4 \mathrm{~kb}$ \\
\hline & & $\mathrm{C} 72$ & AATTTAAAATTGGCATTTCGCC & \\
\hline
\end{tabular}


and incidence of uncomplicated malaria was estimated using a multivariate negative binomial regression model. From a previous analysis in the same children's cohort, age, malaria history and insecticide-treated bed net (ITN) were identified as independent predictors of malaria incidence [19]. These factors were included in the final multivariate analysis to determine the extent to which haptoglobin genotypes affected the incidence of uncomplicated malaria in the children's cohort. Adjusted incidence rate ratios (aIRRs), $\mathrm{P}$ values and 95\% confidence intervals were calculated. All statistical tests were two-tailed and P-values less than 0.05 were considered significant.

\section{Results}

\section{Study population}

A total of 434 cohort children were actively followed up for 1 year and the incidence of malaria (annual episodes per child) was determined. Of the 434 children, 2.5\% (11/434) did not provide an adequate blood sample for subsequent analysis of DNA. The remaining 423 children were included in the host genetics studies. A majority of the study participants (96.7\%) were of Basoga ethnic tribe. Sixty-five percent $(275 / 423)$ were within the age range of 3-9 years and only 35\% (148/423) were under 3 years of age. The mean age was 3.9 years $(\mathrm{SD}: \pm 2.3)$. Slightly over half of the study participants $(52.7 \%)$ were males. At recruitment, mean haemoglobin was $12 \mathrm{~g} / \mathrm{dL}$ (SD: \pm 1.5$)\{$ normal range $=8.8-12.5 \mathrm{~g} / \mathrm{dL}\}[24]$ and mean weight was $15.5 \mathrm{~kg}(\mathrm{SD} \pm 5.2)$. The predominant blood groups were $\mathrm{O}^{+}(39.4 \%)$ and $\mathrm{B}^{+}(30.4 \%)$.

\section{Malaria occurrence and indicators in the children's cohort}

A majority of the guardians of study participants (94.6\%) reported that their children had experienced fever during the past 6 months preceding enrolment into the study. At enrolment to the study, approximately $40 \%$ (168 of the 423 children) had parasitaemia, with a median parasitaemia of 575 parasites/ $\mu \mathrm{L}$ [inter quartile range $(\mathrm{IQR})=225-2750 / \mu \mathrm{L}]$. About $88.2 \%$ of the participants' guardians (373/423) reported owning and using an insecticide treated bed net (ITN) within their households. Four hundred and three participant's guardians $(95.3 \%)$ reported having ever administered an anti-malarial drug to the enrolled child. Throughout the 1 -year of longitudinal follow up in this study, malaria episodes were not registered among 217 out of 423 children (51.3\%). Among those who experienced malaria episodes (206 children; 48.7\%) during the 1 year of follow up, the range of annual episodes per child was 1 to 9 .

\section{Prevalence of haptoglobin genotypes in the children's cohort}

Haptoglobin genotyping was performed successfully for 398 samples by determining the presence or absence of $935 \mathrm{bp}, 1.2 \mathrm{~kb}$ and $1.4 \mathrm{~kb}$ DNA fragments corresponding to the Hp2, Hp1S and Hp1F genotypes, respectively. The Hp1-1, Hp2-1 and Hp2-2 genotypes were found in 41\%, $36.2 \%$ and $22.9 \%$ of the cohort children, respectively. The overall allele frequency for the Hp1 allele was $59 \%$, while $\mathrm{Hp} 2$ allele occurred at an allele frequency of $41 \%$. The distribution of the Hp genotypes in the study cohort is presented in Table 2.

\section{Relationship between haptoglobin genotypes and incidence of uncomplicated malaria in the children's cohort}

This study is an extension of a longitudinal study carried out previously on the same cohort of children [19]. In this children's cohort, a total of 414 new episodes of malaria were recorded during one year of longitudinal follow up. These episodes comprised of a child being unwell, having any level of parasitaemia and having a fever either at the time of visit to the study clinic or within the previous $24 \mathrm{~h}$. The overall incidence of these episodes was 0.98 per child/year. Peak incidence (1.25 episodes/child/ year) occurred between the age range of $1-3$ years, which was about 1.8 times the incidence for older children in the age range of 5-9 years (0.70 episodes/child/year). These episodes of ongoing or recent (past $24 \mathrm{~h}$ ) febrile illness, that were accompanied by $P$. falciparum infection, were included in the final multivariate negative binomial regression model to determine the extent to which they were affected by the haptoglobin genotype after adjusting for other independent determinants of malaria incidence identified in an earlier study in the same children's cohort [19]; namely age, malaria history, and ITN use.

There was no statistically significant difference in the distribution of the $\mathrm{Hp}$ genotypes among children who did and did not experience uncomplicated malaria

Table 2 Haptoglobin genotypes in the study cohort

\begin{tabular}{lcllll}
\hline Hp Genotypes & $\begin{array}{l}\text { Number } \\
\mathbf{N}(\%)\end{array}$ & $\begin{array}{l}\text { Genotype } \\
\text { frequency, } \mathbf{n}(\%)\end{array}$ & $\begin{array}{l}\text { Allele } \\
\text { frequency, } \mathbf{n} \\
\text { (\%) }\end{array}$ \\
\hline 1S-1S & $25(6.3)$ & Hp1-1 & $163(41)$ & Hp1 & $235(59)$ \\
1S-1F & $35(8.8)$ & Hp2-1 & $144(36.2)$ & Hp2 & $163(41)$ \\
1F-1F & $103(25.9)$ & $H p 2-2$ & $91(22.9)$ & & \\
2-1S & $55(13.8)$ & & & & \\
2-1F & $89(22.4)$ & & & & \\
2-2 & $91(22.9)$ & & & & \\
Total & $398(100.0)$ & Total & $398(100.0)$ & Total & $398(100.0)$ \\
\hline
\end{tabular}


throughout the year as shown in Table 3. Crude malaria incidence rates /child/year were 1.16 for the Hp 1-1genotype, 0.86 for Hp 2-1 and 1.01 for individuals carrying the Hp 2-2 genotype. Malaria incidence rates/child/ year for the Hp1 and Hp2 alleles were 0.993 and 0.987 , respectively. After adjusting for known determinants of malaria incidence (age, malaria history and ITN use), the incidence rates of uncomplicated malaria for children carrying the Hp 2-2 genotype and those with the $\mathrm{Hp}$ $2-1$ genotype were statistically similar $(\mathrm{P}=0.41)$. Also, no difference in the incidence of uncomplicated malaria was observed between children carrying the $\mathrm{Hp} 1-1$ genotype and those having the Hp $2-1$ genotype $(\mathrm{P}=0.84)$ or between Hp 2-2 Vs Hp 1-1 genotypes $(\mathrm{P}=0.50)$ as shown in Table 4.

\section{Discussion}

Haptoglobin genotypes, Hp1-1, Hp2-1 and Hp2-2 were found in $41 \%, 36.2 \%$ and $22.9 \%$ of the cohort children, respectively. The overall allele frequency was $59 \%$ for the $\mathrm{Hp} 1$ allele and $41 \%$ for the Hp2 allele. However, no association with incidence of uncomplicated malaria was found. The present findings differ from results of

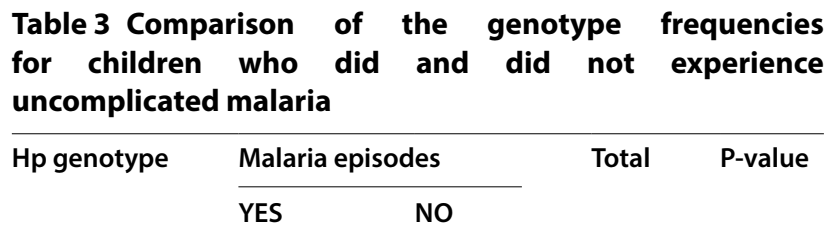

\begin{tabular}{lrrrr}
\hline \multicolumn{6}{l}{$\begin{array}{l}\text { Genotype frequency (\%) } \\
\text { Hp 1-1 }\end{array}$} & & & \\
Others & $118(50.2)$ & $117(49.8)$ & 235 & \\
Hp 1-1 & $82(50.3)$ & $81(49.7)$ & 163 & 0.985 \\
Hp 2-1 & & & & \\
Others & $129(50.8)$ & $125(49.2)$ & 254 & \\
Hp 2-1 & $71(49.3)$ & $73(50.7)$ & 144 & 0.490 \\
Hp 2-2 & & & & \\
Others & $152(49.5)$ & $155(50.5)$ & 307 & \\
Hp 2-2 & $48(52.7)$ & $43(47.3)$ & 91 & 0.588 \\
\hline
\end{tabular}

Others- Sum of all the other Hp genotypes prospective cohort studies carried out among Kenyan children, in which the Hp 2-2 genotype was associated with lower incidence of clinical malaria $[13,14]$. In a different cohort study that was carried out among two ethnically different populations of Mali, the Hp2-2 phenotype was found to be associated with a higher susceptibility to P. falciparum infection in Dogon, but not in Fulani tribe [15]. The findings of the present study and those of earlier studies show variability in the influence of Hp genotypes on malaria susceptibility among the populations studied. The observable differences in the associations reported may be partly explained by the epistatic associations between the Hp genotypes and other genetic markers. However, the present study only assessed the main Hp genotypes. Other Hp genotypes and promoter polymorphisms that could affect plasma Hp levels were not investigated.

In addition, Hp genotypes have been shown to influence plasma Hp levels $[9,10]$ needed in systemic regulation of haem and prevention of haem-induced oxidative tissue damage during $P$. falciparum infections $[8,25]$. This may be particularly important in controlling severe disease. Thus, it is possible that the Hp genotypes may have a greater role in determining malaria severity rather than malaria incidence. However, in the present study, only incidence of uncomplicated malaria was measured. Severity of infection was not assessed. The influence of Hp genotypes on severe malaria has been reported in a few case-control studies [11, 17]. Additional studies of influence of haptoglobin genotypes on $P$. falciparum malaria severity are needed to further understand the role of these genotypes in malarial protection.

The Hp1 allele was present at an allele frequency of $59 \%$, yet no influence on the incidence of uncomplicated malaria by the Hp1 allele was observed. This is also in line with some earlier studies that found no clear associations between the Hp 1 allele and malaria susceptibility $[14,16]$. Instead, the Hp1-1 phenotype was associated with higher levels of tumour necrosis factor (TNF) and interferon gamma (IFN- $\gamma$ ) in an earlier study [15], suggesting that this allele may have been maintained by protection from other infections [14]. Since only a handful

Table 4 Effect of host Hp genotype on incidence of malaria

\begin{tabular}{|c|c|c|c|c|c|c|}
\hline \multirow[t]{2}{*}{ Hp genotype } & \multicolumn{2}{|c|}{ Malaria } & \multirow[t]{2}{*}{ No. of new episodes } & \multirow{2}{*}{$\begin{array}{l}\text { Adjusted incidence rate } \\
\text { ratio }\end{array}$} & \multirow[t]{2}{*}{ P-value } & \multirow[t]{2}{*}{$95 \% \mathrm{Cl}$} \\
\hline & No & Yes & & & & \\
\hline Hp 2-1 & 73 & 71 & 137 & Reference & - & - \\
\hline $\begin{array}{l}\text { Hp 1-1 } \\
\text { Hp 2-2 } \\
\text { Hp 1-1 }\end{array}$ & $\begin{array}{l}81 \\
43 \\
81\end{array}$ & $\begin{array}{l}82 \\
48 \\
82\end{array}$ & $\begin{array}{r}168 \\
95 \\
168\end{array}$ & $\begin{array}{l}1.03 \\
1.16 \\
\text { Reference }\end{array}$ & $\begin{array}{l}0.839 \\
0.405 \\
-\end{array}$ & $\begin{array}{l}0.760-1.403 \\
0.818-1.644 \\
-\end{array}$ \\
\hline Hp 2-1 & 73 & 71 & 137 & 0.97 & 0.839 & $0.713-1.317$ \\
\hline Hp 2-2 & 43 & 48 & 95 & 1.12 & 0.501 & $0.800-1.579$ \\
\hline
\end{tabular}


of studies have investigated the role of Hp genotypes in determining malaria susceptibility yet providing equivocal findings, more extensive studies in different populations are needed to confirm these associations.

\section{Conclusions}

Haptoglobin genotypes, Hp1-1, Hp2-1 and Hp2-2 were found in $41 \%, 36.2 \%$ and $22.9 \%$ of the cohort children, respectively. The overall allele frequency was $59 \%$ for the $\mathrm{Hp} 1$ allele and $41 \%$ for the $\mathrm{Hp} 2$ allele. Association of $\mathrm{Hp}$ genotypes with incidence of uncomplicated malaria was not observed. This lack of detectible association with uncomplicated malaria suggests that these alleles may have been maintained by protection from other infections. Similar studies in different settings are needed to confirm these findings.

\begin{abstract}
Abbreviations
RBC: Red blood cell; ROS: Reactive oxygen species; Hb: Haemoglobin; Hp: Haptoglobin; CD 163: Cluster of differentiation 163; RDT: Rapid diagnostic test; ACT: Artemisinin-based combination therapy; IFN- $\gamma$ : Interferon-gamma; TNF: Tumour necrosis factor; HIV: Human immunodeficiency virus; WHO: World Health Organization; EIR: Entomological inoculation rate; EDTA: Ethylene diamine tetraacetic acid; DNA: Deoxyribonucleic acid; PCR: Polymerase chain reaction; alRR: Adjusted incident rate ratio; IQR: Inter quartile range; SD: Standard deviation; ITN: Insecticide-treated bed net.
\end{abstract}

\section{Acknowledgements}

We are grateful to the Iganga cohort children, parents and guardians for allowing participation in the study. We thank the clinical team and all members from the Malaria Subprogram at the Department of Biochemistry, Makerere University College of Health Sciences for technical support. Special thanks to Levi Mugenyi for his guidance in the statistical analysis.

\section{Authors' contributions}

$\mathrm{CL}$ participated in study design, data collection and laboratory analysis. GS and FK conceived the study, supervised data collection and ensured quality of the laboratory results. All authors participated in the writing and review of the manuscript. All authors read and approved the final manuscript.

\section{Funding}

The research leading to these results received funding from the European Community's Seventh Framework Programme (FP7/2007-2013) under grant agreement $N^{\circ} 242095$ (EVIMALAR). We wish to acknowledge the financial support received from research collaborations under Sida/SAREC - Makerere University - Karolinska Institutet and Uppsala Universitet. We appreciate the financial support of the European and Developing Countries Clinical Trials Partnership (EDCTP) received under grant no. IP.2007.3110.001.

\section{Availability of data and materials}

The clinical and laboratory datasets used and /or analysed during this study are available from the corresponding author upon request.

\section{Ethics approval and consent to participate}

The clinical study and all study protocols were approved by the School of Medicine Research and Ethics Committee of the College of Health Sciences, Makerere University and by the Uganda National Council for Science and Technology (approval number HS 765). All participants provided written informed consent. All children received appropriate treatment for other attendant medical conditions.

\section{Consent for publication}

Not applicable.

\section{Competing interests}

The authors declare that they have no competing interests.

\section{Author details}

${ }^{1}$ School of Biomedical Sciences, College of Health Sciences, Makerere University, PO Box 7072, Kampala, Uganda. ${ }^{2}$ Habib Medical School, Faculty of Health Sciences, Islamic University in Uganda (IUIU), Kampala Campus, Uganda.

${ }^{3}$ Department of Medical Biochemistry and Microbiology, Uppsala University, Uppsala, Sweden. ${ }^{4}$ Department of Biochemistry, Uganda Christian University School of Medicine, PO BOX 4, Mukono, Uganda.

Received: 17 July 2020 Accepted: 19 November 2020

Published online: 26 November 2020

\section{References}

1. WHO. World malaria report. Geneva, World Health Organization. 2017.

2. de Mendonca VR, Goncalves MS, Barral-Netto M. The host genetic diversity in malaria infection. J Trop Med. 2012;2012:940616.

3. Schantz-Dunn J, Nour NM. Malaria and pregnancy: a global health perspective. Rev Obstet Gynecol. 2009;2:186-92.

4. Ferreira A, Balla J, Jeney V, Balla G, Soares MP. A central role for free heme in the pathogenesis of severe malaria: the missing link? J Mol Med . 2008;86:1097-111.

5. Gozzelino R, Soares MP. Heme sensitization to TNF-mediated programmed cell death. Adv Exp Med Biol. 2011;691:211-9.

6. Schaer CA, Deuel JW, Bittermann AG, Rubio IG, Schoedon G, Spahn DR, et al. Mechanisms of haptoglobin protection against hemoglobin peroxidation triggered endothelial damage. Cell Death Differ. 2013;20:1569-79.

7. Kristiansen M, Graversen JH, Jacobsen C, Sonne O, Hoffman HJ, Law SK, et al. Identification of the haemoglobin scavenger receptor. Nature. 2001;409:198-201.

8. Carter K, Worwood M. Haptoglobin: a review of the major allele frequencies worldwide and their association with diseases. Int J Lab Hematol. 2007;29:92-110.

9. Imrie H, Fowkes FJ, Michon P, Tavul L, Hume JC, Piper KP, et al. Haptoglobin levels are associated with haptoglobin genotype and alpha+ -Thalassemia in a malaria-endemic area. Am J Trop Med Hyg. 2006;74:965-71.

10. Fowkes FJ, Imrie H, Migot-Nabias F, Michon P, Justice A, Deloron P, et al. Association of haptoglobin levels with age, parasite density, and haptoglobin genotype in a malaria-endemic area of Gabon. Am J Trop Med Hyg. 2006;74:26-30.

11. Atkinson SH, Uyoga SM, Nyatichi E, Macharia AW, Nyutu G, Ndila $C$, et al. Epistasis between the haptoglobin common variant and alpha+thalassemia influences risk of severe malaria in Kenyan children. Blood. 2014;123:2008-16.

12. Kasvosve I, Gomo ZA, Gangaidzo IT, Mvundura E, Saungweme T, Moyo VM, et al. Reference range of serum haptoglobin is haptoglobin phenotype-dependent in blacks. Clin Chim Acta. 2000;296:163-70.

13. Nyakeriga AM, Troye-Blomberg M. Haptoglobin phenotypes and iron status in children living in a malaria endemic area of Kenyan coast. Acta Trop. 2013;126:127-31.

14. Atkinson SH, Mwangi TW, Uyoga SM, Ogada E, Macharia AW, Marsh $\mathrm{K}$, et al. The haptoglobin 2-2 genotype is associated with a reduced incidence of Plasmodium falciparum malaria in children on the coast of Kenya. Clin Infect Dis. 2007;44:802-9.

15. Perdijk O, Arama C, Giusti P, Maiga B, Troye-Blomberg M, Dolo A, et al. Haptoglobin phenotype prevalence and cytokine profiles during Plasmodium falciparum infection in Dogon and Fulani ethnic groups living in Mali. Malar J. 2013;12:432.

16. Mendonca VR, Luz NF, Santos NJ, Borges VM, Goncalves MS, Andrade $\mathrm{BB}$, et al. Association between the haptoglobin and heme oxygenase 1 genetic profiles and soluble CD163 in susceptibility to and severity of human malaria. Infect Immun. 2012;80:1445-54.

17. Bienzle U, Eggelte TA, Adjei LA, Dietz E, Ehrhardt S, Cramer JP, et al. Limited influence of haptoglobin genotypes on severe malaria in Ghanaian children. Trop Med Int Health. 2005;10:668-71. 
18. Idro R, Williams TN, Gwer S, Uyoga S, Macharia A, Opi H, et al. Haptoglobin HP2-2 genotype, alpha-thalassaemia and acute seizures in children living in a malaria-endemic area. Epilepsy Res. 2008;81:114-8.

19. Lwanira CN, Mukasa MK, Swedberg G, Kironde F. Frequency of RANTES gene polymorphisms and their association with incidence of malaria: a longitudinal study on children in Iganga district. Uganda Malar J. 2015;14:341.

20. de Onis M, Onyango AW, Borghi E, Garza C, Yang H, Group WHOMGRS. Comparison of the World Health Organization (WHO) Child Growth Standards and the National Center for Health Statistics/WHO international growth reference: implications for child health programmes. Public Health Nutr. 2006:9:942-7.

21. WHO. Guidelines for the treatment of malaria. Geneva, World Health Organization, 2006

22. $\mathrm{MOH}$ : Uganda Clinical Guidelines. National guidelines on management of common conditions. Kampala, 2010.
23. Yano A, Yamamoto Y, Miyaishi S, Ishizu H. Haptoglobin genotyping by allele-specific polymerase chain reaction amplification. Acta Med Okayama. 1998:52:173-81.

24. Lugada ES, Mermin J, Kaharuza F, Ulvestad E, Were W, Langeland N, et al. Population-based hematologic and immunologic reference values for a healthy Ugandan population. Clin Diagn Lab Immunol. 2004;11:29-34.

25. Asleh R, Guetta J, Kalet-Litman S, Miller-Lotan R, Levy AP. Haptoglobin genotype- and diabetes-dependent differences in iron-mediated oxidative stress in vitro and in vivo. Circ Res. 2005;96:435-41.

\section{Publisher's Note}

Springer Nature remains neutral with regard to jurisdictional claims in published maps and institutional affiliations.
Ready to submit your research? Choose BMC and benefit from:

- fast, convenient online submission

- thorough peer review by experienced researchers in your field

- rapid publication on acceptance

- support for research data, including large and complex data types

- gold Open Access which fosters wider collaboration and increased citations

- maximum visibility for your research: over $100 \mathrm{M}$ website views per year

At BMC, research is always in progress.

Learn more biomedcentral.com/submissions 